\title{
THE FUNCTIONAL AND CLINICAL ANATOMY OF THE MITRAL VALVE
}

\author{
BY \\ J. C. VAN DER SPUY \\ From the Department of Thoracic Surgery, University of Pretoria, South Africa
}

Received October 16, 1957

This paper is based largely on personal observations of normal and stenosed mitral valves. Some aspects that are new and some that are not in keeping with present-day concepts will be discussed.

The mitral valve is a unit that consists of a so-called fibrous "ring," of two unequal cusps, of two sets of papillary muscles, and of numerous chordæ tendineæ. When two triangular leaflets are attached at their bases to the whole circumference of a ring and their corresponding free margins are brought into apposition, then a cone is formed. The mitral valve consisting, as it does, of two cusps, each somewhat triangular and each attached at its base to the mitral ring, is, therefore, when the cusp margins are in contact, cone-shaped. The significance of and the necessity for an "elongated" mitral "cone" was appreciated by William Harvey in 1628.

In a cone-shaped valve, marginal contact alone would not give the same firm and complete valve closure as would total obliteration of the lumen of the cone when there is complete contact between the inner surfaces of the cusps. To obtain such surface contact a force is required to act on the cone from below. This force is the intraventricular systolic pressure. The mitral valve is a flat cone. Had it been a circular cone, then considerable excursion of the cusps, with more wear and tear, and an unduly high subvalvular pressure, and therefore a high systemic pressure, would have been required to close the lumen of the valve-cone during systole.

The antero-medial cusp is a hinged extension into the cavity of the left ventricle of the posterolateral aortic root. The hinge is the corresponding antero-medial half of the mitral "ring" and is formed by the common fibrous origins of the postero-lateral half of the aortic root, of the anteromedial cusp, and the major part of two aortic cusps. As the base of this mitral cusp is attached to the origin from the aortic root of two adjacent aortic cusps, the antero-medial half of the mitral "ring" is bi-concave (Fig. 1). Had the antero-medial half of the mitral "ring" been semi-circular or semi-ovoid, then the entire base of the antero-medial cusp could not have hinged on the entire postero-lateral half of the root of the aorta.

The postero-lateral half of the mitral "ring" is formed by the common fibrous origins of the postero-lateral cusp and of the corresponding part of the left atrium and of the base of the left ventricle (Fig. 2). (The anterior half of the left atrium has a fleshy origin from the upper surface of the base of the antero-medial cusp close to the mitral "ring.") As the base of the left ventricle is concave, the base of the postero-lateral cusp is convex; thus the shape of the posterior half of the mitral "ring" is semi-ovoid. Had the mitral "ring" occupied the whole of the base of the left ventricle, then its posterior half would have been semi-circular.

The two papillary muscle groups arise from the wall of the ventricle opposite, but distal to, the commissural margins of the cusps. They are therefore known as the antero-lateral and the posteromedial groups. Whereas their bases are attached to the ventricle at about the junction of the upper and middle thirds, their apices project into the upper third of the ventricular cavity and come to lie somewhat close to the commissural margins of the cusps. 
The chordæ tendineæ fan out from the apical zones of one group of papillary muscles to be attached to the margins and under surfaces of the ipso-lateral halves of the cusps. By approximating the apical and commissural zones of the cusps they convert the ring-and-cusp unit into a cone-shaped valve. The more cranial members pass somewhat more steeply towards the upper commissural margins and under surfaces, whereas the more caudally placed chordæ tendineæ pass more horizontally towards the apical zones of the cusps. The more centrally placed chordæ tendineæ of the antero-medial cusp appear somewhat thicker and stronger (Sokoloff et al., 1950) and are attached to the cusp at right angles to the margins of the mitral cone (Fig. 3). During diastole the hinged antero-medial cusp swings downwards and forwards into the path of the left ventricular outflow. Tension exerted on these strong chordæ tendineæ by the papillary muscles during early systole draws the anteromedial cusp towards the postero-lateral one and so prevents its displacement towards the aortic root by the high ejection force of left ventricular systole. Subsequent tension on these chordæ tendineæ will exert a flattening force on the mitral cone.

The nature of the distribution of the attachments of the chordæ tendineæ to the ventricular surface of the cusps plays a most important role in the mechanism of mitral valve closure. These chordæ tendineæ of the

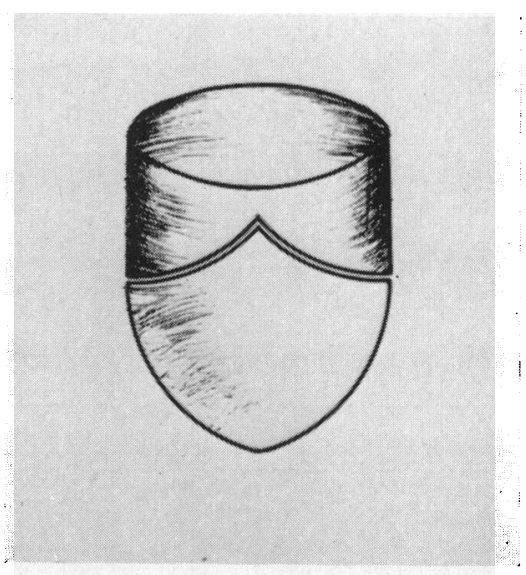

FIG. 1.-The bi-concave base of the antero-medial cusp is attached to the bi-convex postero-lateral half of the root of the aorta. antero-medial cusp are attached only to the peripheral zone of the cusp (Fig. 4). The basal somewhat trigonal portion of the antero-medial cusp is therefore much thinner than the peripheral portion and its excursion towards the atrium during systole is not directly restricted by the chordæ tendineæ. This mobile "trigone" can therefore billow towards the cavity of the left atrium during systole (Fig. 5). The chordæ tendineæ of the postero-lateral cusp, however, are inserted into its entire ventricular surface, excluding the basal zone (Fig. 6). The base of the cusp, therefore, being more mobile than the rest of the cusp, bulges forwards during systole and causes flattening of the valve by reducing the postero-anterior diameter of the base of the cone, thus reducing the degree of cusp excursion required to cause total obliteration of the lumen of the valve cone. As the base of the postero-lateral cusp is attached to a segment of the base of the left ventricle via the mitral "ring," this basal portion of the cusp remains concave during systole.

The antero-medial cusp is much longer than the postero-lateral one (Fig. 7). The mitral cone, therefore, has an oblique base, i.e. the mitral "ring" is set obliquely. Had the cusps been of equal length, then complete flattening of the base of the cone would have been necessary for total cusp surface contact, i.e. total valve closure, to have taken place. Instead the antero-medial cusp is long and its thin mobile "trigone" lies opposite the concave base of the postero-lateral cusp. In systole, therefore, the former billows upwards and backwards to fit snugly into the concavity of the latter, resulting in complete valve cone closure (Fig. 5).

As the postero-lateral root of the aorta, from which the antero-medial cusp is suspended, is convex posteriorly, the mitral "ring," as seen from above, is somewhat kidney-shaped (Fig. 8). In the neutral position the body of the antero-medial cusp, therefore, has a natural tendency to bulge towards the concavity of the postero-lateral cusp. As the antero-medial cusp is suspended from the aortic root it can readily swing backwards and forwards in systole and diastole, and as the mobile "trigone" lies opposite the posterior half of the mitral "ring," the mouth of the cone at this level is an oval opening in diastole and a crescentic slit in systole (Fig. 5).

The base of the left ventricle accommodates the circular (as seen from above) root of the aorta and, lying postero-lateral to it, the kidney-shaped mitral "ring" (Fig. 9). During systole the base 


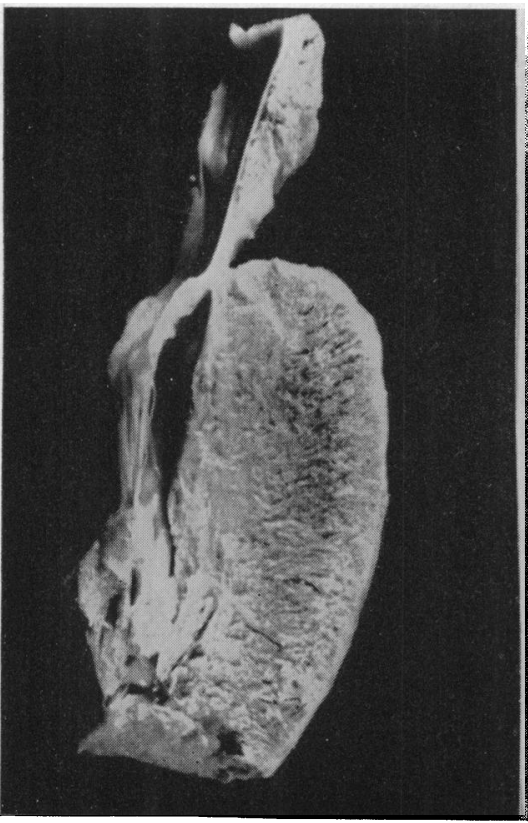

Fig. 2.-The postero-lateral half of the mitral "ring" gives attachment to the corresponding portions of the base of the left ventricle and of the left atrium and to the postero-lateral cusp.

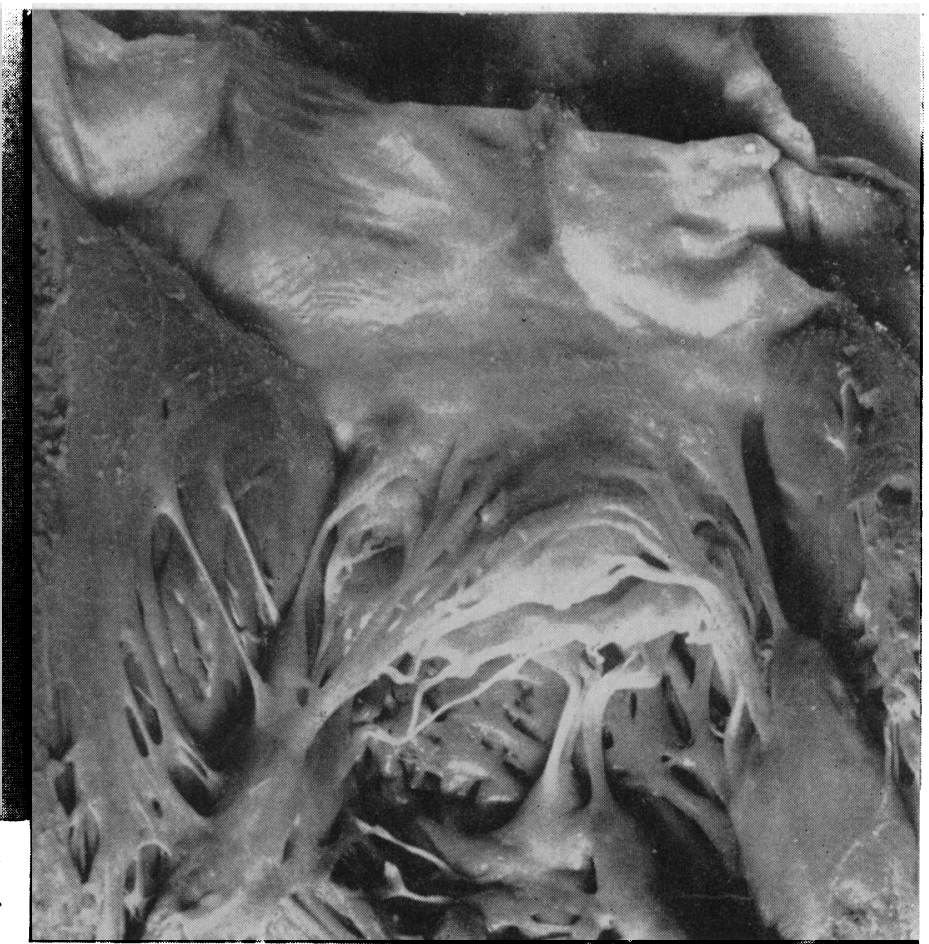

FIG. 3.-The chordæ tendineæ fan out from the apical regions of the papillary muscles to be attached to the margins and ventricular surfaces of the ipso-lateral halves of both cusps. The central group of chordæ tendineæ of the antero-medial cusp are thick and strong and are attached to the cusp at right angles to its commissural margin.

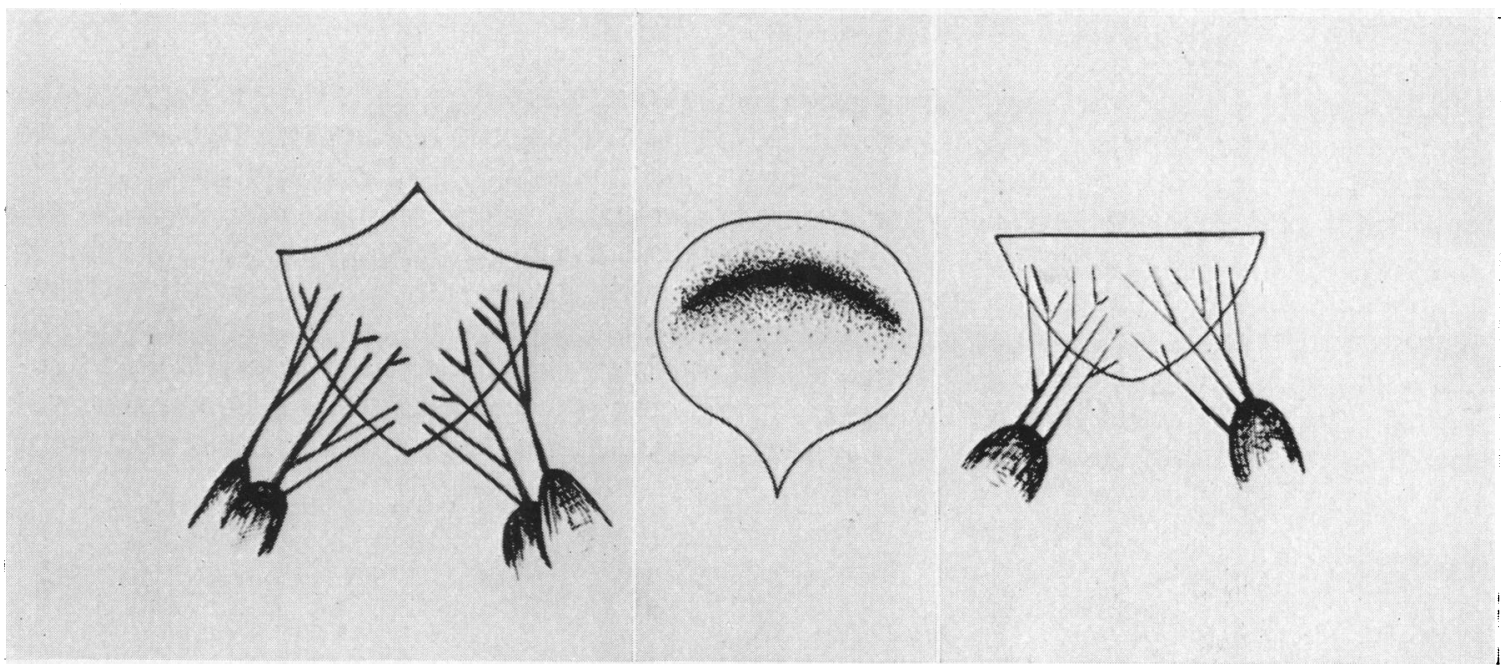

Fig. 4

Fig. 5

FIG. 6

Fig. 4.-The surface chordæ tendineæ of the antero-medial cusp are attached to the peripheral zone of the cusp only.

FIG. 5.-During systole the mobile "trigone" of the antero-medial cusp fits snugly into the concavity of the mobile base of the postero-lateral cusp. The mouth of the cone is a crescentic slit in systole.

FIG. 6. - The surface chordæ tendineæ of the postero-lateral cusp are attached to its entire ventricular surface.

$2 \mathrm{~K}$ 
of the left ventricle is reduced in circumference (Brock, 1952). Simultaneously the elastic aorta, subjected to the full force of the blood ejected by the left ventricle, expands. As the antero-medial cusp is attached to the postero-lateral root of the aorta, and as the postero-lateral cusp is attached to the base of the left ventricle, ventricular systole produces flattening of the mitral "ring" with consequent approximation of the cusps.

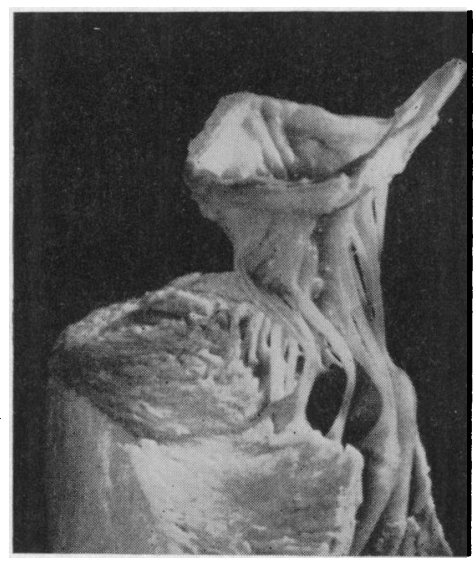

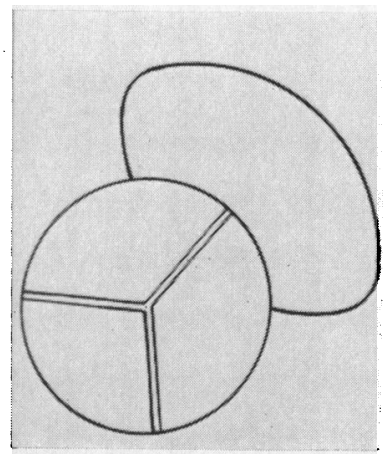

Fig. 8

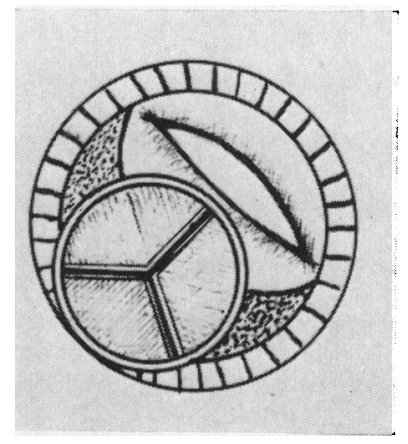

FIG. 9

FIG. 7

Fig. 7.-The antero-medial cusp is much longer than the postero-lateral one. As the apical zones of the cusps correspond, the cone has an oblique base.

FIG. 8.- As the postero-lateral root of the aorta, from which the antero-medial cusp is suspended, is convex posteriorly, the mitral "ring," as seen from above, is somewhat kidney-shaped.

Fig. 9.-The base of the left ventricle accommodates the circular (as seen from above) root of the aorta and the kidney-shaped mitral "ring."

\section{The Normal Mechanism of Mitral Valve Closure}

When, at the onset of systole, the pressure in the left ventricle exceeds that in the left atrium, mitral valve closure is brought about by a series of mechanisms which act either simultaneously or in very rapid succession.

As a result of the rising subvalvular tension, and as a result of the pull by the papillary muscles on the chordæ tendineæ, the antero-medial cusp, hinged at the aortic root, rotates backwards and the postero-lateral cusp, hinged at the posterior half of the mitral "ring," rotates forwards. This cusp rotation is brought to a halt after a very brief moment when the apical and commissural margins of the cusps meet. From this moment onwards the mitral valve is closed, although not firmly so. As there is a progressive rise in the left ventricular pressure, so there is a progressive increase in the extent of cusp surface contact (Fig. 10); and as the thin and mobile "trigone" of the antero-medial cusp balloons upwards and backwards towards the concave base of the posterolateral cusp, so the mobile base of the postero-lateral cusp is forced against the ballooning anteromedial cusp, resulting in complete valve closure. Fig. 11 indicates how flattening of the mitral

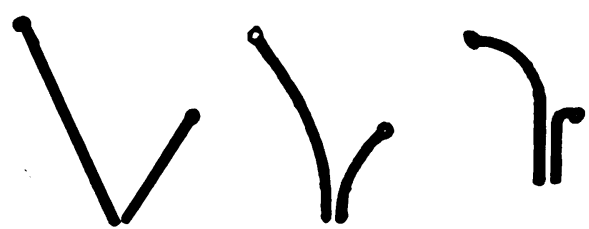

Fig. 10. - Rise in the left ventricular pressure causes progressive increase in the extent of cusp surface contact.

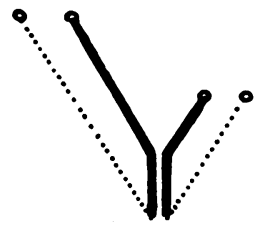

FIG. 11.-Flattening of the mitral "ring" between the root of the aorta and the base of the left ventricle. 
"ring" between the root of the aorta and the base of the left ventricle causes an increase in the extent of cusp surface contact.

From the above description it will be seen that the construction of the mitral valve is such that it closes by means of progressive cusp surface contact in a direction from the apex towards the base of the valve, i.e. the antero-medial cusp rolls on the postero-lateral cusp from the latter's apex towards and as far as the latter's base. The principle involved is the same as is employed by, e.g. wrestlers when adopting a rolling motion to break the force of a fall when striking the mat. Had the cusps been vertical leaflets, meeting head on in systole, then the contact force would have been twice that of left ventricular pressure. The rolling mechanism of mitral valve closure is therefore of the greatest importance in protecting the cusps against injury by the high left ventricular pressure. As the antero-medial cusp is for practical purposes a direct continuation of the corresponding portion of the aorta into the cavity of the left ventricle, it can be readily appreciated how the systolic force which causes rolling mitral valve closure "rolls" off the under surface of the antero-medial cusp into the lumen of the aorta.

\section{The Mechanism whereby Stenosis of the Mitral Valve is Produced}

During diastole the commissural margins of the cusps form the sides of a triangular opening, the apex of which is close to the mitral "ring." During systole the commissural margins of the cusps are in apposition and this triangular space is obliterated. Although there are very brisk and forceful backward and forward movements of these commissural margins during systole and diastole, the very apex of the triangular space remains relatively immobile. Material deposited in the acute angle of this immobile apex will cause fusion between the adjacent commissural margins in rheumatic heart disease. With progressive silting up (Tweedy, 1956) of the apex of this triangular diastolic opening, a stage is reached when the further deposition of material in the apex results in its replacement by a concave margin. It would, therefore, appear that the somewhat constant size of 1 by $\frac{1}{2} \mathrm{~cm}$. and the oval shape of the opening of a fully stenosed mitral valve (Brock, 1952) are determined by the gradual replacement of the acute commissural angle on either side of the stenosing opening by a concave margin which brings the silting up process to an end. The size of the opening does not appear to depend on fusion between the commissural margins secondary to fusion at centrally-situated critical areas of tendon insertion as postulated by Brock (1952).

\section{Closing Mechanism of a Stenosed Valve}

Examination of an autopsy specimen of a fully stenosed mitral valve will show such a valve to be, anatomically, incompetent also. But it is well known that a tightly stenosed valve is only rarely associated with significant incompetence. What then is the mechanism preventing functional incompetence in an anatomically incompetent valve? As explained above, mitral valve closure is normally brought about in the first instance by apical and commissural zone contact followed by cusp surface contact in a direction from the apex of the cone towards, and as far as, the base of the postero-lateral cusp. Because of the presence of the firm oval opening at the apex of the closing mitral valve, marginal contact cannot take place in this region. Nor can surface contact close the lumen of the apical zone. As the left ventricular pressure rises, so the cusps are forced closer and closer together, causing a progressive reduction in the antero-posterior diameter of the supra-stenotic valve lumen, until finally the cusps meet above the opening to obliterate the lumen of the basal part of the cone, thus preventing prolonged regurgitation through the rigid and anatomically incompetent apex of the valve.

Supra-stenotic valve closure appears to be wholly responsible for the production of the "presystolic" murmur, whereas supra-stenotic cusp surface contact seems to be partly responsible for the characteristic delayed (Cossio and Berconsky, 1943) and accentuated (Dock, 1933) first heart sound. It is believed that the presystolic murmur results from an increased blood flow through the narrowed mitral orifice towards the end of diastole (Wood, 1956). Whereas valve closure normally starts at the margins of the cusps at the onset of systole, in mitral stenosis these margins 
are fused except at the apex, where a firm oval opening is interposed, and valve closure only takes place during early systole by means of supra-stenotic cusp surface contact. This means that in mitral stenosis the valve apex is still open at a time when normally it is closed and that regurgitation takes place during early systole through a progressively decreasing supra-stenotic valve lumen. As there is a progressive decrease in the antero-posterior diameter of the lumen, so there is a progressive rise in the left ventricular pressure and, therefore, in the force and rate of flow of the systolic regurgitation until supra-stenotic valve closure finally takes place (Fig. 12). The characteristic "presystolic" crescendo murmur so produced, therefore, appears to be caused by regurgitation during early ventricular systole. As the murmur precedes the first heart sound, produced by delayed supra-stenotic valve closure, it appears to occur prior to ventricular systole.

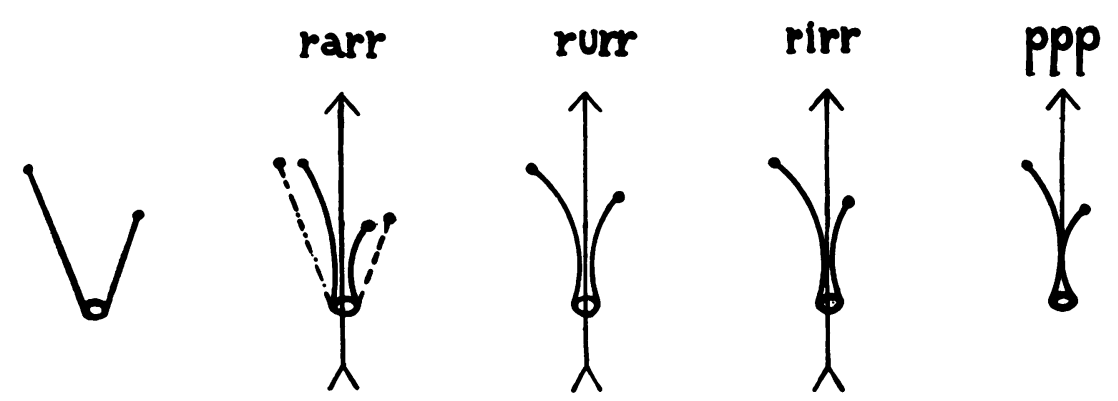

Fig. 12.-In mitral stenosis regurgitation takes place during early systole through a progressively decreasing suprastenotic valve lumen. As there is a progressive decrease in the antero-posterior diameter of this lumen, so there is a progressive rise in the left ventricular pressure and, therefore, in the force and rate of flow of the systolic regurgitation, until supra-stenotic valve closure takes place, producing the characteristic "presystolic" crescendo murmur.

If the mechanism of supra-stenotic valve closure is accepted, then it becomes obvious that the direction of the blood flow during early systole through the closing valve is from the left ventricle into the left atrium. Then the "presystolic" murmur cannot be produced by atrial systole in late diastole. The "presystolic" murmur, therefore, appears to be a pre-delayed-first-sound ventricular systolic murmur. Had the direction of flow of the blood which causes the "presystolic" murmur been from the left atrium towards the left ventricle, then there would have been a short break between the end of the murmur and the first sound, representing the time required for valve excursion from the diastolic to the systolic position. Then the "presystolic" murmur would not have ended with an accentuated first sound (Wood, 1956). The length of the "presystolic" murmur seems to depend on the rate of excursion and mobility of the cusps, on the length of the antero-posterior diameter of the stenosed opening and on the presystolic position of the cusps.

During diastole the outflow from the left atrium is partially obstructed and the cusps, fused at their margins, are forced downwards into the cavity of the ventricle. The presystolic position of the cusps is determined by the length of diastole. When the ventricular filling time is short, the cusps are still maximally displaced towards the ventricle, and ventricular systole causes maximal and rapid cusp excursion towards the atrium with the production of a loud first sound. When diastole is long, blood filling the ventricular cavity slowly approximates the cusps, and when ventricular systole occurs, minimal cusp excursion causes valve closure with the production of a soft sound (Dock, 1933). It would seem, however, that this wide range of cusp excursion is not the only reason why the first sound is accentuated in mitral stenosis. As supra-stenotic valve closure implies late cusp surface contact, the valve is closed by a left ventricular pressure that is higher than the pressure that normally causes valve closure. Also, as the rolling mechanism which breaks the force of cusp contact is upset, owing to the interposition of the stenosed opening at the apex of the valve, the cusp closing force is distributed over a smaller cusp contact area, and the cusps meet more or less head on. As, therefore, the cusp-closing force is high, the contact surface reduced, and the direction of contact head on, the first sound in mitral stenosis is characteristically loud, abrupt, and highpitched.

Mitral valve closure in mitral stenosis is delayed because early ventricular systole does not cause cusp excursion towards the closed position, but, as the left atrial pressure in such cases is elevated, it merely overcomes the pressure gradient across the mitral valve (Cossio and Berosky, 1943). Only after the pres- 
sures on either side of the valve have become equal will further ventricular systole result in valve closure. This delay is indicated by an increase in the time interval between the onset of the QRS complex of the electrocardiogram and the first heart sound of the phonocardiogram (Wells, 1954). Kelly (1955) examined this Q-1 interval in 100 patients with cardiac lesions of all types, except those involving the mitral valve, and in 75 patients with mitral stenosis as the only lesion. He concluded that with a Q-1 interval of longer than $\mathbf{0 . 0 7}$ second a mitral stenosis of significant degree could be taken for granted. It is suggested, however, that the mechanism of valve closure in mitral stenosis, namely supra-stenotic cusp surface contact in early systole, is a contributory cause of the increased Q-1 interval.

In atrial fibrillation the presence or absence of the murmur depends on the length of diastole (Messer et al., 1951). When diastole is long the mid-diastolic murmur begins with the opening snap and fades out completely before the first heart sound. If diastole is short, the murmur, beginning in the same way, lasts throughout diastole to the very beginning of the first heart sound; and "since the first sound is delayed, the murmur is not only presystolic, but actually extends for a short interval after the beginning of electrical systole." When diastole is short the cusps are still maximally displaced towards the left ventricle when systole takes place (Dock, 1933). Then there will be maximal systolic regurgitation through the apex of the mitral cone until supra-stenotic valve closure takes place. When diastole is long there is a greater filling of the left ventricle and the cusps will float towards the closed position and, when systole occurs, only slight excursion of the cusps is required to produce supra-stenotic valve closure with the production of a soft first heart sound (Dock, 1933) and an absent pre-delayed-sound murmur.

In cusps of normal length, supra-stenotic cusp surface contact is limited by two important factors, namely by thickening of the cusps and by shortening of the chordæ tendineæ. It is obvious that thickening of the cusps, through fibrosis or calcification, will reduce the systolic excursions of the mobile "trigone" of the antero-medial cusp and of the mobile base of the postero-lateral cusp and so interfere with normal valve function. Shortening of the chordæ tendineæ, too, is a most important cause of regurgitation, whether the valve be stenosed or not. During mitral valve closure the apex of the cone is necessarily displaced upwards towards the atrium, but this cannot take place because of shortening of the chordæ tendineæ which results in the cusp remaining more or less straight during systole, i.e. valve closure cannot take place.

As supra-stenotic valve closure fails, so various degrees of regurgitation will occur. The degree of regurgitation and the extent of cusp surface contact are inversely proportional. Therefore, provided the thickness and the mobility of the cusps remain constant, there is an inverse proportion between the loudness of the first sound and the extent of the leak. Thus when the mitral sound is loud and snapping there will be no, or only minimal, mitral regurgitation and the sound heard on auscultation will be rrruppp. Similarly the murmur of combined mitral stenosis and regurgitation may be rrupps, rrupthth or rrushshsh. As the " $p$ " representing cusp surface contact decreases, so the systolic murmur increases. The character of the first heart sound in mitral stenosis depends largely on the heart rate (Wynn, 1953). When there is rapid cusp excursion from the fully open to the closed position of the valve, supra-stenotic cusp surface contact improves. Thus after even slight exertion the murmur rrupthth of combined stenosis and regurgitation may, for example, change to the murmur rrruppp of pure stenosis. It therefore seems that auscultation to determine the presence of mitral regurgitation in association with stenosis will be reliable only when done under basal conditions. In this respect it is of interest to note that although a stenosed valve may be incompetent when the subject is at rest, the incompetence may disappear completely when he is active.

\section{Summary AND CoNClusions}

The posterior half of the mitral "ring" is semi-ovoid; its anterior half is bi-concave. The papillary muscles and chordæ tendineæ prevent prolapse of both cusps into the cavity of the left atrium and of the antero-medial cusp towards the root of the aorta; they convert the cusp-and"ring" unit into a cone, which they help to flatten during systole. 
The surface chordæ tendineæ of the antero-medial cusp are attached only to the marginal zone of its ventricular surface. Those of the postero-lateral cusp are attached to the entire ventricular surface of the cusp excepting the basal zone.

The billowing "trigone" of the long antero-medial cusp fits snugly into the bulging concave base of the shorter postero-lateral cusp. During systole the mitral "ring" becomes flattened between the postero-lateral root of the aorta and the base of the left ventricle. During mitral valve closure the antero-medial cusp rolls on the postero-lateral cusp in a direction from its apex towards, and as far as, its base, thereby reducing the cusp contact force.

The mechanism whereby mitral valve stenosis is produced is discussed. Anatomically the stenosed mitral valve is also incompetent. Functional incompetence, however, is prevented by means of supra-stenotic cusp surface contact.

The "presystolic" murmur appears to be an early systolic murmur occurring prior to a delayed first sound. The length of the "presystolic" murmur seems to depend on the rate of excursion and mobility of the cusps, on the length of the antero-posterior diameter of the stenosed opening, and on the presystolic position of the cusps.

The accentuated first sound is caused not only by the increased span of cusp excursion in systole, but also by delayed (i.e. supra-stenotic) cusp surface contact and by a disturbance of the rolling mechanism of valve closure. The result is that the cusps are closed by a higher systolic force distributed over a smaller contact area of cusps now meeting more or less head on. The first sound delay is caused not only by the pressure gradient across the mitral valve but also by the delayed (i.e. supra-stenotic) cusp surface contact.

In atrial fibrillation the presence of the pre-delayed-sound murmur depends on the presystolic position of the cusps.

In cusps of normal length supra-stenotic cusp surface contact is reduced by thickening of the cusps and by shortening of the chordæ tendineæ. As supra-stenotic cusp surface contact decreases, so mitral incompetence increases.

I wish to express my thanks to Mr. Theo Marais for the photographs and to Miss S. Kloppers for the drawings.

\section{REFERENCES}

Brock, R. C. (1952). Brit. Heart J., 14, 489.

Cossio, P., and Berconsky, I. (1943). Rev. Argent. Cardiol., 10, 162.

Dock, W. (1933). Arch. intern. Med., 51, 737.

Harvey, W. (1628). The Works of William Harvey. Sydenham Society, London, 1847, p. 80.

Kelly, J. J., Jr. (1955). Amer. Heart J., 19, 862.

Messer, A. L., Counihan, T. B., Rappaport, M. B., and Sprague, H. B. (1951). Circulation, 4, 576.

Sokoloff, L., Elster, S. K., and Righthand, N. (1950). Circulation, 1, 782.

Tweedy, P. S. (1956). Brit. Heart J., 18, 173.

Wells, B. (1954). Brit. Heart J., 16, 261.

Wood, P. (1956). Diseases of the Heart and Circulation. Eyre and Spottiswoode, London.

Wynn, A. (1953). Brit. Heart J., 15, 214. 